\title{
LOS DAÑOS CORPORALES Y SU VALORACIÓN, UNA MIRADA DESDE EL DERECHO ESPAÑOL
}

\author{
THE PERSONAL INJURY AND THEIR VALUATION, A LOOK FROM \\ THE SPANISH LAW
}

Fecha Recepción: 01/08/2011

Darío Parra Sepúlveda ${ }^{1}$

Fecha Aceptación: 30/09/2011

\begin{abstract}
Resumen
En el presente artículo se aborda la problemática de los daños corporales, atendiendo a las herramientas de que disponen los ordenamientos jurídicos para establecer criterios objetivos en la valoración de esta clase de perjuicios, limitando así la amplia discrecionalidad que los órganos judiciales gozan en esta materia. Centramos particularmente nuestro estudio en el sistema de valoración de los daños corporales derivados de accidentes de circulación en la ley 30/1995 de ordenación y supervisión de los seguros privados, actualmente vigente en el ordenamiento jurídico español. Se destacan además, aquellos aspectos del sistema que han sido objeto del arduo debate doctrinal y jurisprudencial en España, entregando algunas luces sobre el pretendido establecimiento de un sistema legal comunitario de valoración de los daños corporales al amparo de la Unión Europea.
\end{abstract}

Palabras clave: Daño Corporal, Baremo español, Daño extrapatrimonial.

\begin{abstract}
In this article, we discuss the difficulties that arise from attempts to establish legal tools in order to measure the severity of personal injuries. Those tools, which aim at rendering the valuation of such injuries more objective, limit the broad discretion that courts use to enjoy in such matters. We focused our study principally on the injury rating system resulting from road accidents in the law 30/1995 of regulation and supervision of private insurance currently in force in the Spanish legal system. It highlights those aspects of the system that have been the subject of heated debate between Spain doctrine and jurisprudence, a debate which sheds light on the ostensible establishment of a common system of valuation scales of personal injuries in the European Union.
\end{abstract}

Key words: Personal injury, valuation scales Spanish, non pecuniary loss.

\footnotetext{
Abogado. Licenciado en Ciencias Jurídicas. Máster en Derecho Privado y @ C Doctorado en Derecho, Universidad Carlos III de Madrid, España. dparra@letrados.cl
}

doi: 10.7770/RCHDYCP-V2N2-ART44 


\section{SUMARIO}

I. Generalidades.

II. Consecuencias de los daños corporales y la problemática de su valoración.

III. La valoración de los daños corporales derivados de accidentes de circulación en la ley 30/1995 de ordenación y supervisión de los seguros privados en el ordenamiento jurídico español.

IV. Características del sistema.

V. La pretendida inconstitucionalidad del sistema de valoración de daños corporales en el Derecho español.

VI. Hacia la búsqueda de un sistema legal comunitario de valoración de los daños corporales.

VII. Conclusiones.

\section{Generalidades}

Desde la aparición de los sistemas de responsabilidad objetiva, la culpa ha dejado de ocupar la posición de honor ejercida desde la dictación de los códigos decimonónicos herederos del code, siendo reemplazada en la actualidad por el daño, el cual asume un papel clave en estos nuevos sistemas de responsabilidad civil de corte más objetivo ${ }^{2}$.

Que en la actualidad sea el daño y no la culpa el que ocupe un lugar de preeminencia en los sistemas de responsabilidad civil, implica una necesaria revisión y ampliación de las tradicionales categorizaciones de los perjuicios, puesto que en una sociedad posindustrial, esencialmente tecnificada y donde los individuos -mejor informados sobre sus derechos- no están dispuestos a soportar ningún tipo de menoscabo sin que este le sea debidamente resarcido, la clásica distinción entre daños patrimoniales y no patrimoniales no entrega respuestas acordes a las dificultades con que se encuentran los jueces en su difícil misión de administrar justicia.

Así las cosas, dentro de los daños extrapatrimoniales surge una interesante clasificación que tiene en consideración si el interés lesionado recae en la esfera de la persona y sus respectivos atributos ya sea corporales o espirituales, afectando en

2 En este sentido Naveira Zarra, Maita, El resarcimiento del daño en la responsabilidad civil extracontractual, Editoriales de Derecho Reunidas, Madrid, 2006, p. 34; sobre el actual protagonismo de la culpa dentro de la responsabilidad civil, se ha pronunciado la española Medina Alcoz, María, La culpa de la víctima en la producción del daño extracontractual, Dykinson, Madrid, 2003, pp. 42 y ss. 
consecuencia intereses que no son objeto de transacciones comerciales y cuya estimación pecuniaria no puede sujetarse a valores de mercado ${ }^{3}$. De este modo, dentro de los daños no patrimoniales se incluyen: A) Los daños corporales, entendidos estos como atentados o lesiones a la salud, tanto física como psíquica, de las personas ${ }^{4}$; y B) Los daños morales, que son aquellos en que el interés afectado recae en la esfera puramente espiritual, identificándose con las lesiones o atentados a los sentimientos y afectos más íntimos de la persona o a los derechos de la personalidad.

En este sentido, cabe resaltar que uno de los pasos más relevantes dentro de la evolución del derecho de la responsabilidad civil, es la creciente atención dada a las lesiones contra la integridad del cuerpo humano ${ }^{5}$. Dicho interés no ha sido fruto del azar, sino que responde a la conjugación de una serie de factores que han ido de la mano con el crecimiento y desarrollo de las sociedades contemporáneas, a saber: A) La mecanización y tecnificación de los procesos productivos, han provocado que en un par de décadas se hayan multiplicado considerablemente tanto el número de daños producidos -accidentes laborales, de circulación, de consumo, etc.- como la gravedad de los mismos, en otras palabras, "las potencialidades de la vida contemporánea guardan una inevitable correlación con un aumento exponencial de los riesgos cotidianos" $^{\prime 6}$; B) Es de notar -principalmente en países desarrollados- un incremento en la adopción de seguros de responsabilidad civil, lo cual ha contribuido a que los perjudicados reclamen la reparación de los daños padecidos ya no directamente contra el causante del daño, sino que en contra de la aseguradora ${ }^{7}$, despersonalizando así al causante del perjuicio, "a través de la llamada socialización de la responsabilidad civil"8; C) se aprecia que una vez producido el daño, ya no se asume como una consecuencia del azar, designios divinos o la mala suerte, sino que todos los esfuer-

\footnotetext{
Vicente Domingo, Elena, Los daños corporales: tipología y valoración. Bosch, Barcelona, 1994, p. 49.

Vicente Domingo, Elena, Los daños corporales: tipología y valoración obr. cit. pp. 49 y 50; en un sentido similar: Sainz Moreno, Fernando, Transmisión hereditaria de la indemnización por daños morales (Sobre la reforma del parágrafo 847 del Código Civil alemán y la situación en el Derecho español) /en/ Revista de Administración Pública, n. ${ }^{\circ}$ 124, 1991, España, p. 445, nota n. ${ }^{\circ} 2$; y García Serrano, Francisco de Asís, El daño moral extracontractual en la jurisprudencia civil /en/ Anuario de Derecho Civil, T. XXV, 1972, España, pp. 802 y 803.

5 Pradel, Xavier, Le préjudice Dans le droit civil de la responsabilicé. Librairie Genérale de Droit et de Jurisprudence, Paris, 2004, pp. 299 y ss., agrega este autor que el perjuicio corporal es considerado como el daño que más importa en el sistema jurídico francés, ocurriendo lo mismo en la mayoría de los derechos extranjeros, por cuanto "es la dignidad eminente de la persona humana y la inviolabilidad de su cuerpo que justifican la protección reforzada consagrada a la indemnización del perjuicio corporal".

${ }_{6}$ Barros Bourie, Enrique, Tratado de Responsabilidad Extracontractual, Editorial Jurídica de Chile, Santiago, 2006, pp. 319 y 320.-

7 Naveira Zarra, Maita, El resarcimiento del daño en la responsabilidad civil extracontractual obr. cit. pp. 33 y 34 .

8 Vicente Domingo, Elena, El daño /en/ Reglero, Fernando (coord.), Tratado de Responsabilidad Civil, Navarra, Aranzadi, 2008, p. 305.
} 
zos se dirigen necesariamente a la búsqueda de un responsable ${ }^{9}$ a quien exigir la correspondiente indemnización; y D) Porque al hablar de daños corporales, en una sociedad modernista, esencialmente globalizada y marcada por una concepción hedonista e individualista de las relaciones humanas, nos referimos sin lugar a dudas al bien más preciado por toda persona, como es la salud y la integridad física y psíquica ${ }^{10}$.

Una vez establecida la importancia y actualidad del estudio de esta especie de perjuicio no patrimonial, podemos precisar que el daño corporal es un daño extrapatrimonial y personal que recae en la esfera del propio cuerpo o en la integridad física y psíquica de la persona. Además es un daño reparable, puesto que el no considerar al daño corporal en sí mismo como un coste que ha de repararse, supone tomar la decisión de que lo soporte, en definitiva, el que lo sufre, porque de lo que no hay duda es de la existencia material del perjuicio ${ }^{11}$.

A lo apuntado anteriormente, cabe agregar una característica no menos importante relativa a la dificultad que conlleva su "reparación", ya que si indemnizar es dejar "indemne", es evidente que una obligación indemnizatoria solo puede tener por objeto reponer un patrimonio al estado en que se encontraba antes de producirse el perjuicio. Sin embargo, el principio enunciado respecto de los daños corporales tiene una escasa aplicación, debido a la particular naturaleza no económica de estos perjuicios, lo que viene a complejizar aún más el panorama de establecer a su respecto reglas indemnizatorias racionales.

En este orden de ideas, resulta pertinente resaltar la imposibilidad práctica de aplicar la restitutio in integrum respecto de quien ha sufrido, por ejemplo, la amputación de un brazo, ya que ni la reposición de otro ortopédico, o el pago de una elevada suma de dinero, constituirían una indemnización íntegra para la víctima en el sentido apuntado ${ }^{12}$. Como puede apreciarse en el caso anterior y en muchos otros similares, en los que el perjuicio recae sobre intereses extrapatrimoniales, no será

9 Vicente Domingo, Elena, obr. cit. p. 305.

10 Sobre el particular véase, entre otros, los interesantes trabajos escritos en España sobre el tema: Vicente Domingo, Elena, Los daños corporales: tipología y valoración, Bosch, Barcelona, 1994; Reglero Campos, Fernando. Responsabilidad civil y seguro en la circulación de vehículos de motor /en/ Reglero, Fernando (coord.), Tratado de Responsabilidad Civil, Aranzadi, Navarra, 2006, pp. 1074 a 1150; Sabater Bayle, Elsa, El baremo para la valoración de los daños corporales, Navarra, Aranzadi, 1998; Medina Crespo, Mariano, La valoración civil del daño corporal: Bases para un tratado, Dykinson, Madrid, 1999.

11 Vicente Domingo, Elena, obr. cit. p. 348; en igual sentido De Ángel Yágüez, Ricardo, La reparación de daños personales en el Derecho español, con referencias al Derecho comparado /en/ Revista Española de Seguros n 57, 1989, España, p. 48.

12 Tampoco dejaría "indemne" a la víctima por ejemplo: el pago de una renta vitalicia al huérfano que sobrevive a sus padres en un accidente; o el proporcionar cuidados a quien ha visto deteriorada su salud mental por consecuencia de la actuación dañosa de un tercero. 
posible indemnizar en estricto rigor. Aspirándose solo a una compensación para la víctima, puesto que el bien agredido se encontraría fuera del comercio humano, no integrando en consecuencia el concepto económico de activo patrimonial ${ }^{13}$.

\section{Consecuencias de los daños corporales y la problemática de su valoración}

Al referirnos a los daños corporales, no podemos dejar de lado sus importantes consecuencias que terminan repercutiendo -cada vez con mayor frecuencia e intensidad- tanto en el patrimonio del lesionado como en sus intereses extrapatrimoniales. De esta forma, un perjuicio corporal puede provocar a la víctima de la lesión ciertas secuelas de naturaleza muy distinta, distinguiéndose en doctrina: A) Unas de índole estrictamente pecuniario, Ilamadas consecuencias económicas del daño corporal, las que a su vez pueden revestir el carácter de presentes o futuras; y B) Otras cuya entidad es ajena a lo pecuniario, denominadas consecuencias no económicas del daño corporal ${ }^{14}$.

Centrando nuestro análisis en las consecuencias económicas de la lesión corporal, podemos observar que a raíz del atentado a la integridad física o psíquica de un individuo, se producen para este dos grandes tipos de consecuencias pecuniarias: En primer lugar, se distinguen los gastos médicos, de ambulancia, transporte, de hospitalización, de farmacia y similares, a los que el perjudicado directo ha hecho frente con su patrimonio, constituyendo estas consecuencias una suerte de damnum emergens ${ }^{15}$; $\mathrm{Y}$ en segundo lugar, se encuentran aquellas pérdidas de rentas o ingresos correlativos a la incapacidad física padecida o que padece aún el lesionado, las que a su vez reunirían las características del clásico lucrum cessans ${ }^{16}$.

13 Sabater Bayle, Elsa, El baremo para la valoración de los daños corporales, Aranzadi, Navarra, 1998, p. 17.

14 Vicente Domingo, Elena, obr.cit. p. 355; comparten esta idea los franceses: Viney, Geneviéve y Jourdain, Patrice, Les conditions de la responsabilicé /en/ Jacques Ghestin (Dir.), Traite de Droit, $3^{a}$ edición, Librairie Genérale de Droit et de Jurisprudence, Paris, 2006, pp. 46 y ss.; Bacache-Gibeili, Mireille, Les obligations, La Responsabilité civile extracontractuelle /en/ Larroumet, Christian (Dir.), Droit Civil, Tomo V, Paris, Economica, 2007, pp. 376 y 377; Le Tourneau, Philippe, La responsabilidad civil, Legis, Bogotá, 2004. (Traducción de Javier Tamayo), p. 71; y Pradel, Xavier, obr. cit. pp. 304 y ss.

15 Cabe destacar que el tratadista francés Carbonnier, califica a esta especie de consecuencias que acarrea el daño corporal, directamente como un damnum emergens, para la víctima. Carbonnier, Jean, Droit Civil, Les obligations, Tomo IV, Presses Universitaires de France, Paris $22^{\text {a }}$ edición, 2000, p. 381; en igual sentido la española Vicente Domingo, Elena, obr. cit. p. 355.

16 Vicente Domingo, Elena, obr. cit. 71; p. 355; En igual sentido se pronuncian los franceses Le Tourneau, Philippe, obr. cit. p. 71; Viney, Geneviéve, Jourdain, Patrice, obr.cit. pp. 46 y 47; Pradel, Xavier. obr. cit. p. 305; Bacache-Gibeili, Mireille, obr. cit. pp. 376 y 377. 
Sobre la cuantificación de este tipo de consecuencias, consideramos que ha de establecerse en razón del cálculo de los dos elementos que lo integran, a saber: el daño emergente y el lucro cesante. Como puede apreciarse, es respecto de este tipo de consecuencias del daño corporal -meramente económicas- donde cobra su correcto sentido la obligación de dejar indemne a la víctima del hecho dañoso. Por tanto, si a raíz de un atropello a un peatón este sufre una lesión física, no hay duda de que la pérdida de su trabajo -lucrum cessans-, los gastos hospitalarios, gastos de terapia recuperativa -damnum emergens-, entre otros, son susceptibles de ser indemnizados y no solamente compensados, como ocurriría en el caso de la amputación de una pierna ${ }^{17}$, debiendo ser tratados como un ejemplo más de deuda de valor.

Para completar esta referencia a las consecuencias de los daños corporales, podemos afirmar que el ataque a la integridad corporal arrastra indiscutiblemente, además de los ya mencionados menoscabos materiales, una serie de perjuicios netamente extrapatrimoniales -consecuencias no económicas del daño corporal-. En otras palabras, el daño corporal no solo no se agota en sí mismo y además produce consecuencias en el orden patrimonial o pecuniario, sino que también causa diversos perjuicios de carácter estrictamente moral ${ }^{18}$. De allí que los perjuicios sexuales, estéticos, o como se plantea en el derecho francés, le préjudice d'agrément, constituyen sin lugar a dudas un conjunto de consecuencias de índole no económica o extrapatrimonial del daño corporal ${ }^{19}$.

La complejidad que presentan las consecuencias no económicas de los daños corporales, ha dificultado la labor de su valoración o cuantificación pecuniaria, debido principalmente a que los atributos de la personalidad (vida, salud o integridad física y psíquica) por definición carecen de valor económico. Por mucho que se pretenda asignar un valor pecuniario a un sujeto, lo cierto es que tal valoración será por esencia inexacta o meramente consensual, puesto que la vida humana, la integridad física, la salud o los órganos de una persona tienen por su naturaleza un valor incalculable y menos en dinero ${ }^{20}$.

17 Sabater Bayle, Elsa, obr. cit. pp. 18 y 19.

18 Vicente Domingo, Elena, obr. cit. p. 359.

19 Como anota Bacache-Gibeili, La jurisprudencia francesa, mantiene respecto de este tipo de perjuicio una definición amplia, entendiéndolo como la "privación de los placeres de una vida normal". Se trata por tanto de la privación provisional o definitiva total o parcial de los placeres de la vida o de las alegrías de la existencia. En esta acepción amplia y objetiva, del préjudice d’agrément engloba todas las dificultades y las confusiones sentidas por la víctima en su vida cotidiana, tales como pérdida del gusto y del olfato, la privación de la lectura, la imposibilidad de pasear, de practicar un deporte o de viajar. Bacache-Gibeili, Mireille, obr. cit. p. 380.

20 Sabater Bayle, Elsa, obr. cit. p. 16; sentido compartido por De Ángel Yágüez, Ricardo, Tratado de responsabilidad civil, Civitas, Madrid, 1993, p. 692. 
Haciéndonos cargo de los problemas presentes tanto en la avaluación como en la reparación de las consecuencias no económicas del perjuicio corporal, queda patente la inviabilidad de una reparación integral en esta clase de daños, debiendo conformarse el juzgador con entregar una compensación a la víctima por el padecimiento sufrido. En la práctica el resarcimiento de este tipo de consecuencias, ordinariamente debiese tomar la forma de una suma de dinero entregada a la víctima, con la cual si bien no se repara todo el daño sufrido, se intenta que con ella, el lesionado pueda darse otro tipo de satisfacciones que le ayuden a aligerar en lo posible las consecuencias negativas del perjuicio. Es así como, a grosso modo, toma forma la función compensatoria o satisfactiva de la indemnización pecuniaria, respecto de esta clase de daños no patrimoniales ${ }^{21}$.

En efecto, es esta función compensatoria o satisfactiva de la reparación dineraria lo que hace que debamos reflexionar previamente sobre ciertas consideraciones económicas que no son de fácil solución ${ }^{22}$, más aún, si planteamos la utilización de un sistema de reglas racionales para la avaluación de los perjuicios extrapatrimoniales en ordenamientos, como por ejemplo el chileno, donde los órganos judiciales gozan de una amplia discrecionalidad para la determinación del quantum resarcitorio en caso de daños extrapatrimoniales ${ }^{23}$.

Como punto de partida en nuestra reflexión, compartimos aquel planteamiento doctrinario que critica una absoluta discrecionalidad de los tribunales de justicia para la determinación del quantum resarcitorio en caso de estos perjuicios no patrimoniales ${ }^{24}$.

21 Díez Schwerter, José Luis, El daño extracontractual, Jurisprudencia y doctrina, Editorial Jurídica de Chile, Santiago, 1997, pp. 247 a 249.

22 En este sentido se ha pronunciado, Domínguez Hidalgo, Carmen, El daño moral, Tomo II, Editorial Jurídica de Chile, Santiago, 2000, p. 711.

23 Sobre las facultades discrecionales que actualmente gozan los tribunales chilenos en la valoración de los perjuicios extrapatrimoniales, pueden citarse las siguientes sentencias de la Corte Suprema: CS, 7.1.2003, GJ 271, 96, donde se establece que el monto de la indemnización es apreciado por los jueces del fondo "en atención al sufrimiento, dolor, o molestia que el hecho ilícito ocasiona en la sensibilidad física o en los sentimientos o afectos de una persona, lo que constituye una apreciación subjetiva que queda entregada solo al criterio y discernimiento de aquellos", no siendo objeto de control por vía de casación en el fondo; En similar sentido, CS, 27.3.2002, GJ 261, 80, afirma que el daño moral "afecta la integridad espiritual de una persona, el que es apreciado por el juez de acuerdo a los antecedentes del proceso y la equidad". Un análisis sobre la situación jurisprudencial chilena al respecto lo encontramos en: Díez Schwerter, José Luis, obr. cit. pp. 242 a 258; Corral Talciani, Hernán, Lecciones de responsabilidad civil extracontractual, Editorial Jurídica de Chile, Santiago, 2003, pp. 167 y 168, en especial pp. 174 a 177; Barros Bourie, Enrique, obr. cit. pp. 317 y ss.

24 En este sentido Barrientos Zamorano, Marcelo, El resarcimiento por daño moral en España y Europa. Ratio Legis, Salamanca, 2007, p. 466; Barros Bourie, Enrique, obr. cit. pp. 317 y ss; Corral Talciani, Hernán, obr. cit. pp. 167 y 168; Domínguez Hidalgo, Carmen, obr. cit. pp. 713 y 714; Díez Schwerter, José Luis, obr. cit. p. 256; Rodríguez Grez, Pablo, Responsabilidad extracontractual, Editorial Jurídica de Chile: Santiago, 1999, p. 338. 
Como destaca De Ángel, "la valoración del daño corporal constituye un gravísimo problema en la práctica, pues la discrecional apreciación por parte del juez de los daños sufridos, y de la suma de dinero con la que deben ser indemnizados, supone, de un lado, una necesidad: la de atender las particularidades del caso concreto, tan diferentes en cada asunto. Pero, de otra parte, se hace imprescindible un mínimo de homogeneidad (no uniformidad), pues de otro modo se pueden conceder (y de hecho se conceden) indemnizaciones pecuniarias de cuantía muy distante en situaciones muy parecidas entre si" 25 .

Por otro lado, la excesiva discrecionalidad que gozan, en algunos ordenamientos jurídicos, los tribunales de justicia para la determinación del quantum resarcitorio en caso de daños corporales, trae una serie de consecuencias negativas entre las que a modo ejemplar destacamos: A) Atenta contra el principio de igualdad en virtud del cual a daños iguales debiesen atribuírseles indemnizaciones semejantes, con absoluta independencia de la condición de la víctima ${ }^{26}$; B) El establecer como reparación de los daños no patrimoniales sumas excesivas y dispares lleva a un aumento considerable de las primas de seguro, lo que trae como consecuencia el incremento de los precios de ciertas actividades productivas riesgosas, lo que se traduce en que sea la sociedad en su conjunto, y no el autor del perjuicio, la que termine soportando casi la totalidad del peso económico de la indemnización ${ }^{27}$; C) Se produce una mercantilización de este tipo de perjuicios, constituyéndose en definitiva su reparación en una fuente de lucro y especulación ${ }^{28}$; D) Acarrea una situación de inseguridad jurídica que dificulta la posibilidad de asegurar estos daños, creando incentivos imprecisos al cuidado que deben emplear los agentes de riesgo ${ }^{29}$; E) Se produce una perversa tendencia de emplear a este tipo de menoscabos para dar soporte a demandas infundadas e injustificadas o para palear ausencias e insuficiencias de pruebas de daños materiales ${ }^{30}$, lo cual se traduce en un aumento nocivo de la litigiosidad.

Así las cosas, vemos como entregar a la absoluta discrecionalidad de los órganos judiciales la valoración de los daños corporales no soluciona la problemática descrita, al contrario, genera una serie de inequidades e inseguridades que en los sistemas jurídicos europeos se han intentado corregir con el establecimiento de sistemas racionales de valoración de los perjuicios. De esta forma, las consecuencias no eco-

De Ángel Yágüez, Ricardo, obr. cit. p. 692.

26 Barros Bourie, Enrique, obr. cit. pp. 316 y 317, agrega este autor que las "indemnizaciones tiendan a ser mayores cuando el demandado es particularmente solvente y que sean sustancialmente inferiores en el caso inverso".

27 Domínguez Hidalgo, Carmen, obr. cit. p. 711, en igual sentido se ha pronunciado la española Vicente Domingo, Elena, obr. cit. p. 305.

28 En similar sentido, Corral Talciani, Hernán, obr. cit. p. 168.

29 Barros Bourie, Enrique, obr. cit. p. 317.

30 Domínguez Hidalgo, Carmen, obr. cit. p. 711. 
nómicas del daño corporal generan en la práctica una deuda pecuniaria cuya cuantía, en vez de quedar sometida al arbitrio judicial, es determinada a través del establecimiento de tablas o baremos -con diversos matices en su obligatoriedad, según el ordenamiento jurídico ${ }^{31}$-, en los que se incluye un descriptor de todos los casos que se consideran dignos de compensación, acompañando unas cifras compensatorias previamente calculadas ${ }^{32}$.

Estos baremos pueden ser confeccionados con la ayuda conjunta de distintos profesionales del área -médicos, juristas, jueces- o sobre la base de análisis estadísticos -precedentes judiciales de los tribunales superiores-. Por otro lado, las tablas en algunos sistemas son recogidas directamente por el legislador -España, Francia, Bélgica, Italia- y en otros, las prácticas judiciales previas son ordenadas y recogidas de forma sistematizada en publicaciones especializadas, sin una baremación médica anterior-Alemania, Austria, Países Bajos, Inglaterra- ${ }^{33}$.

En lo que sigue, analizaremos de modo crítico el sistema de valoración de daños corporales derivados de accidentes de circulación vigente en el Derecho español, de manera que la experiencia hispana pueda contribuir al desarrollo de un sistema más racional de valoración de perjuicios corporales en el Derecho chileno.

\section{La valoración de los daños corporales derivados de accidentes de circulación en la ley 30/1995 de ordenación y supervisión de los seguros privados en el ordenamiento jurídico español}

Como destaca parte de la doctrina española ${ }^{34}$, la valoración del daño corporal ha dado un giro importantísimo en este país desde la instauración del sistema legal de valoración del daño creado por la Ley 30/1995. Dicho sistema, ha tenido un im-

Sobre el particular, vid. Barrientos Zamorano, Marcelo. obr. cit. pp. 436 a 468.

Sabater Bayle, Elsa, obr. cit. p. 17.

Barrientos Zamorano, Marcelo, obr. cit. p. 465; Barros Bourie, Enrique, obr. cit. p. 318.

34 Entre otros Martín Del Peso, Rafael, La indemnización y valoración de daños y perjuicios derivados de la responsabilidad civil /en/ Seijas, José Antonio (coord.), Responsabilidad civil, Aspectos fundamentales. Sepin, Madrid, 2007, p. 111; En igual sentido también se ha pronunciado buena parte de la doctrina española, destacándose las opiniones de: De Ángel Yágüez, Ricardo, Algunas previsiones sobre el futuro de la responsabilidad civil (con especial atención a la reparación del daño), Civitas, Madrid, 1995, pp. 180 y 181; Medina Crespo, Mariano, La valoración legal del daño corporal: análisis jurídico del sistema incluido en la ley 30/1995, Dykinson, Madrid, 1997; Roca I Trias, Encarna, Derecho de daños: Textos y materiales, 5 a edición, Tirant lo Blanch, Valencia, 2007, pp. 143 y 144. 
portante efecto o fuerza expansiva al proyectarse, lo cual quedaría de manifiesto al constatarse una amplia utilización de este régimen por parte de los tribunales de justicia $^{35}$, incluso para cuantificar daños corporales derivados de otra clase de supuestos distintos de los establecidos en la normativa citada ${ }^{36}$.

Sobre el mencionado sistema de baremación, no pocos agregan que encontraría fundamento no solo en las dificultades propias del perjuicio corporal, mencionadas en los párrafos anteriores, que por lo demás son inherentes a su compleja naturaleza, sino que además consideran que encontraría sustento en que el arbitrio judicial se ha mostrado insuficiente para fijar la indemnización de las consecuencias no económicas del daño corporal ${ }^{37}$.

Por otro lado, desde sus inicios buena parte de la doctrina ha rechazado la inclusión del sistema de baremos en el ordenamiento español, por cuanto el mencionado sistema no tendría como objetivo dar una concreta solución a la supuesta incapacidad de los jueces de valorar el importe de los daños corporales, sino que su principal razón de ser, no sería otra que la creación de un sistema de protección de los intereses de las compañías aseguradoras, permitiéndoles la realización de un cálculo anticipado de las probables indemnizaciones a abonar en caso de lesiones corporales. En este sentido advierte Pantaleón Prieto que alguna de las soluciones a las que llega la norma, "son el escandaloso resultado de haber dejado redactar aquella disposición adicional a los representantes de las compañías aseguradoras, mediante la Dirección General del sector" ${ }^{\prime \prime 3}$.

Asimismo, se ha criticado al sistema de baremos español, señalando que está muy lejos de haber alcanzado el nivel técnico mínimamente aceptable, subrayando que es notorio que en su elaboración han intervenido de forma muy activa las entidades aseguradoras, extrañándose la participación de otros sectores

35 Vid, Martín del Peso, Rafael, obr. cit. pp. 111 y ss.

36 Así lo destacan entre otros: Sabater Bayle, Elsa, obr. cit. pp. 19 y ss.; Roca I Trias, Encarna, obr. cit. pp. 143 y 144; Martín Del Peso, Rafael, obr. cit. p. 111; De Ángel Yágüez, Ricardo, Algunas previsiones sobre el futuro de la responsabilidad civil (con especial atención a la reparación del daño), Civitas, Madrid, 1995, pp. 180 y 181.

37 Vicente Domingo, Elena, obr. cit. pp. 404 y 405; así también piensa Martín Del Peso, Rafael, obr. cit. p. 111.

38 Pantaleón Prieto, Fernando, Sobre la inconstitucionalidad del sistema para la valoración de daños personales de la Ley sobre Responsabilidad Civil y Seguro en la Circulación de Vehículos a Motor /en/ Revista Actualidad Jurídica Civil Aranzadi, n 245, 1996, España, pp. 1 y ss.; con similar tono; Reglero Campos, Fernando, obr. cit. pp. 1075. 
sociales como los representados por las organizaciones de consumidores y usua$\operatorname{rios}^{38}$.

Una vez clarificadas las reales motivaciones del establecimiento de este sistema de valoración de los daños corporales en el ordenamiento jurídico español y teniendo en consideración los antecedentes legislativos de la normativa vigente en la actualidad, puede determinase el momento inicial de esta innovación en las pretensiones de la Orden del Ministerio de Economía y Hacienda español de 5 de marzo de 1991.

De esta forma y a modo de resumen, se aprecian marcadamente tres etapas en la ardua tarea de la valoración del daño personal en el ámbito de los accidentes de circulación en el sistema español. La primera constituye la etapa más amplia y se extiende precisamente hasta marzo de 1991, le sigue un período intermedio de aproximadamente cinco años de duración, en el cual los baremos tienen un carácter meramente orientativo. Finalmente, la tercera etapa se inicia con la entrada en vigor de la nueva normativa el 10 de noviembre de $1995^{39}$.

\section{Características del sistema}

En una aproximación general a la modificación introducida por la Ley 30/1995, respecto del sistema anterior, puede destacarse que dicho cuerpo legal incorpora un sistema de valoración de los daños y perjuicios derivados de los accidentes automovilísticos causados a las personas, en lo que se refiere al seguro obligatorio de automóviles, introduciendo un sistema de baremos en el que, a efectos de establecer una valoración objetiva de los daños producidos, se tienen en cuenta determinadas circunstancias, tales como la edad de la víctima, las lesiones y consecuencias producidas (circunstancias económicas, familiares, laborales, entre otras). Por otro lado, es vinculante para la valoración e indemnización de los accidentes ocasionados con motivo de la circulación de vehículos a motor, excepto cuando las lesiones sean causadas por un delito doloso ${ }^{41}$.

39 Reglero Campos, Fernando, obr. cit. pp. 1075 y 1076. Agrega este autor que: "el sistema quería poner freno a una práctica judicial que iba camino a alcanzar dimensiones desproporcionadas, como era la concesión de cantidades extremadamente elevadas en los casos de grandes invalideces..."

40 Un análisis de la historia del establecimiento de la normativa regulada por la ley 30/1995, la encontramos en Medina Crespo, Mariano, obr. cit. pp. 47 y ss.

41 Roca I Trias, Encarna, obr. cit. p. 143; Barrientos Zamorano, Marcelo, obr. cit. p. 471. 
A su vez, la disposición adicional $8^{a}$ de la norma, modifica y cambia de denominación a la "Ley de Uso y Circulación de Vehículos de Motor", que a partir de ese momento pasa a ser la "Ley Sobre Responsabilidad Civil y Seguro en la Circulación de Vehículos a Motor" -en adelante LRCSCVM-. Dentro de esta última norma, como anexo a la misma se incorpora el "Sistema para la valoración de los daños y perjuicios causados a las personas en accidentes de circulación", conocido coloquialmente como baremo.

Se puede agregar que el "baremo" contenido en ese anexo comprende $11 \mathrm{cri}$ terios (apartado primero), una explicación sobre la aplicación del sistema (apartado segundo) y seis tablas de valoración: "las indemnizaciones básicas por muerte" (Tabla I); los "factores de corrección para las indemnizaciones básicas por muerte" (Tabla II); las "indemnizaciones básicas por lesiones permanentes (incluidos daños morales)" (Tabla III); los "factores de corrección para las indemnizaciones básicas por lesiones permanentes" (Tabla IV); las "indemnizaciones por incapacidad temporal" (Tabla V, dividida en dos apartados: A.- "indemnizaciones básicas", incluidos los daños morales; B.- "factores de corrección") y, finalmente, la tabla referida a "clasificaciones y valoración de secuelas" (Tabla VI) ${ }^{42}$.

Respecto de los daños considerados por el sistema, podemos señalar que a efectos de la aplicación de la LRCSCVM se distinguen fundamentalmente dos tipos de daños: A) los daños "a las personas" que también es aludido con la expresión daños personales, incluyéndose dentro de estos supuestos "al valor de la pérdida sufrida" (normalmente gastos de asistencia médico-hospitalaria y los de entierro y funeral), "las ganancias que se hayan dejado de obtener" (lucro cesante) y los "daños morales"; y B) los "daños a los bienes". De los dos tipos de daños mencionados (a las personas y a los bienes), solo respecto de los primeros su cuantificación ha de realizarse según los criterios del sistema de valoración de los "daños a las personas", establecidos en el anexo de la LRCSCVM. Por su parte, los denominados "daños a los bienes" no quedan sometidos a valoración legal alguna, de forma tal que siguen el régimen general de responsabilidad civil establecido en el artículo 1902 del Código civil español ${ }^{43}$.

A lo señalado cabe realizar algunas consideraciones; por una parte la expresión "daños a las personas", utilizada por la LRCSCVM -como destaca parte de la doctrina española-, es poco afortunada pues resulta evidente que todo tipo de daño afecta en última instancia a la persona, ya sea en su esfera corporal o mental, bien en sus bienes o patrimonio presente o futuro, prescindiendo del concepto de daños corporales que parece ser mucho más apropiado. Por otro lado, al analizar los supuestos que se encuadran dentro del ámbito de aplicación de la LRCSCVM, en principio no se ven razones por las que una misma partida indemnizatoria -lucro cesante- haya de ser in-

42 Martín-Casals, Miquel, Una lectura de la sentencia del tribunal constitucional sobre el baremo /en/ La Ley: Revista jurídica española de doctrina, jurisprudencia y bibliografía, № 6, 2000, España, p. 1852.

43 Reglero Campos, Fernando, obr. cit. p. 1078. 
demnizado de forma distinta según tenga su causa en una lesión corporal o la muerte de una persona, o la tenga en la pérdida o deterioro de un bien material (v. gr. pérdidas de ingresos de un taxista por no poder conducir su taxi $)^{44}$.

Relacionado con esta última cuestión, en lo tocante a la indemnización del lucro cesante futuro, se había presentado una interesante discusión al respecto. El debate se centraba por un lado, en determinar si los perjuicios derivados del lucro cesante futuro, en caso de lesiones permanentes, se encuentran o no incluidos en el baremo establecido en el anexo de la LRCSCVM, y por otro, en caso de ser afirmativa la cuestión anterior, si para la determinación de la cuantía indemnizatoria se deben o no aplicar exclusivamente los criterios establecidos en los factores de corrección consagrados en tabla IV del anexo ${ }^{45}$.

Dicha polémica ha quedado zanjada con lo dispuesto por la reciente Sentencia de la primera sala del Tribunal Supremo español, la cual con fecha 25 de marzo del $2010^{46}$ establece una importante doctrina al respecto.

La importancia de la citada sentencia, radica en que junto con señalar los requisitos que deben concurrir para la aplicación del factor de corrección en las indemnizaciones básicas por lesiones permanentes, consagrados en la tabla IV del anexo, señala expresamente a qué principios deberá sujetarse dicho factor de corrección ${ }^{47}$.

44 Reglero Campos, Fernando, obr. cit. pp. 1078 y 1079.

45 En este orden de ideas, podemos destacar que en más de alguna ocasión se ha intentado ampliar la declaración de inconstitucionalidad, consagrada en la conocida Sentencia del pleno del Tribunal Constitucional de 29 de Junio de 2000 (RC 181, 2000), que por lo demás solo afecta al apartado B) de la Tabla $V$ del Anexo y a los factores de corrección por perjuicios económicos de las Tablas II y IV, que se aplicarían respecto del lucro cesante futuro. Interpretación que a juicio de la $1^{\text {a }}$ Sala del Tribunal Supremo debe ser negativa, y así lo establece expresamente en la sentencia de 25 de marzo de 2010.

46 STS, sala $1^{\text {a }}$ de 25 de marzo de 2010 (JUR 2010/131534).

47 STS, sala $1^{\text {a }}$ de 25 de marzo de 2010 (JUR 2010/131534). Los hechos que motivan la dictación de esta sentencia son los siguientes: El 2 de mayo de 2000 se produjo una colisión entre el vehículo conducido por el demandante y otro vehículo, cuyo conductor falleció, como consecuencia del accidente, el demandante requirió 186 días de hospitalización, 534 días de incapacidad, quedando además con una serie de secuelas. El conductor del primer vehículo presentó demanda contra los herederos del conductor fallecido, causante del accidente y contra su aseguradora reclamando la diferencia entre la suma consignada por la aseguradora y la indemnización que a su juicio le correspondía por incapacidad permanente absoluta, más el lucro cesante que acreditaba por medio de prueba pericial por importe de $143.516 €$. El Juzgado estimó parcialmente la demanda, y concedió, entre otros extremos, una indemnización por incapacidad permanente total por importe de $70.000 €$, pero desestimó la reclamación por lucro cesante por entender que este concepto se encuentra incluido en las cuantías indemnizatorias establecidas en el "baremo" de la LRCSCVM con arreglo al artículo 1.2 LRCSCVM, por lo que no procedía tener en cuenta el informe actuarial aportado con la demanda ni el propuesto por la aseguradora, con sus factores de corrección de variables. Se fijó la indemnización a percibir por el actor en $28.823,17 €$, una vez sustraídas las cantidades ya percibidas por el mismo, y consignadas por la aseguradora, de 17.156,37 € y $144.288,63 €$. La sentencia fue recurrida por la aseguradora y por el demandante, el cual únicamente se opuso al pronunciamiento de desestimación de la 
Luego de una serie de consideraciones, el máximo Tribunal Hispano en la sentencia referida, plasma una interesante postura sobre la determinación de la cuantía del lucro cesante futuro, subrayando que: El factor de corrección de la Tabla IV que permite tener en cuenta los elementos correctores del Anexo, primero, 7, debe aplicarse siempre que: 1) Se haya probado debidamente la existencia de un grave desajuste entre el factor de corrección por perjuicios económicos y el lucro cesante futuro realmente padecido, y 2) Este no resulte compensado mediante la aplicación de otros factores de corrección, teniendo en cuenta la proporción en que el referido factor por incapacidad permanente pueda considerarse razonable, ya que la falta de vertebración de la indemnización por este concepto de que adolece la LRCSCVM no impide que este se tenga en cuenta.

Por último, agrega el Supremo español que: "La aplicación del expresado factor de corrección debe sujetarse, además, a los siguientes principios: A) La determinación del porcentaje de aumento debe hacerse de acuerdo con los principios del Sistema y, por ende, acudiendo analógicamente a la aplicación proporcional de los criterios fijados por las Tablas, para situaciones que puedan ser susceptibles de comparación. De esto se sigue que la corrección debe hacerse en proporción al grado de desajuste probado, con un límite máximo admisible, que en este caso es el que corresponde a un porcentaje del $75 \%$ de incremento de la indemnización básica, pues este es el porcentaje máximo que se fija en el factor de corrección por perjuicios económicos; B) La aplicación del factor de corrección de la Tabla IV sobre elementos correctores para la compensación del lucro cesante, ha de entenderse que es compatible con el factor de corrección por perjuicios económicos, en virtud de la regla general, sobre compatibilidad de los diversos factores de corrección; C) El porcentaje de incremento de la indemnización básica debe ser suficiente para que el lucro cesante futuro quede compensado en una proporción razonable, teniendo en cuenta que el sistema no establece su íntegra reparación, ni esta es exigible constitucionalmente. En la fijación del porcentaje de incremento debe tenerse en cuenta la suma concedida aplicando el factor de corrección por perjuicios económicos, pues, siendo compatible, se proyecta sobre la misma realidad económica; D) El porcentaje de incremento sobre la

reclamación por lucro cesante. La Audiencia Provincial estimó parcialmente el recurso de la aseguradora, considerando correcta la cantidad en su día abonada por la aseguradora por incapacidad permanente total, por hallarse dentro de la horquilla prevista en el sistema de valoración (la cual quedaba fijada implícitamente en la suma de 41.176,98 euros), y desestimó el recurso del demandante fundándose en que no cabe incluir el lucro cesante en el artículo 1.2 LRCSCVM. Contra dicha resolución la parte demandante interpone recurso de casación, cuyo único motivo es el siguiente: "Infracción de las normas aplicables para resolver las cuestiones objeto del proceso y, en concreto, infracción de las normas relativas a la indemnización del lucro cesante ocasionado como consecuencia de una negligencia en la conducción de vehículos a motor. (Artículo 1106 CC en relación con el artículo 1902 del mismo cuerpo legal)". En consecuencia, el Tribunal Supremo Casa la sentencia recurrida en cuanto se refiere a los pronunciamientos sobre desestimación del recurso interpuesto por D. José Luis, que declara sin valor ni efecto alguno y mantiene los pronunciamientos relativos a la estimación del recurso de apelación interpuesto por seguros Zurich, S.A. y en su lugar, estimando en parte la demanda interpuesta por el lesionado, y aplicando la doctrina anteriormente expuesta. Condena a los demandados a que abonen conjunta y solidariamente a la actora la suma de 33.338,80 euros, a los que se sumarán los intereses legales desde la fecha de interposición de la demanda. 
indemnización básica por incapacidad permanente no puede ser aplicado sobre la indemnización básica concedida por incapacidad temporal, puesto que el Sistema de valoración únicamente permite la aplicación de un factor de corrección por elementos correctores de aumento cuando se trata de lesiones permanentes a las que resulta aplicables la Tabla IV"48.

En otro orden de cosas, un interesante rasgo para apuntar sobre el régimen de valoración de daños corporales español, es el del indudable carácter obligatorio y vinculante de la normativa apuntada. De la simple lectura de la ley, y en especial de su exposición de motivos queda clarísima la obligatoriedad del sistema ${ }^{49}$. Con todo, la postura adoptada por los Tribunales Españoles puede ser concentrada en dos grupos $^{50}$ : De un lado se encuentran las decisiones que acatan la obligatoriedad general de la norma ${ }^{51}$; y de otra, las que afirman que las tablas solo sirven para la valoración de los daños con cargo al Seguro Obligatorio y que el exceso se valorará discrecionalmente por el Juez conforme con la prueba ${ }^{52}$.

Otra circunstancia del sistema establecido en la LRCSCVM y que merece ser destacada, dice relación con el punto siete del apartado primero del anexo, en el que se enumeran once reglas explicativas de las tablas. Estas reglas tienen la particularidad de afectar tanto a la valoración del daño como a los criterios de imputación del mismo ${ }^{53}$.

En relación a lo señalado anteriormente, la doctrina española entiende que no caben dudas acerca de que nos encontramos con un sistema de valoración de los daños corporales, que prescinde del principio de la discrecionalidad judicial en materia de valoración ${ }^{54}$. También está claro que el sistema no se apoya en el principio

48 STS, sala $1^{\text {a }}$ de 25 de marzo de 2010 (JUR 2010/131534).

49 De esta forma, en la exposición de motivos de la Ley 30/1995 encontramos que: "Se recoge un sistema legal de delimitación cuantitativa del importe de las indemnizaciones exigibles como consecuencia de la responsabilidad civil en que se incurre con motivo de la circulación de vehículos a motor. Este sistema indemnizatorio se impone en todo caso, con independencia de la existencia o inexistencia de seguro..."

50 Vicente Domingo, Elena, obr. cit. p. 409.

51 A modo de ejemplo podemos citar las siguientes sentencias: Sentencia de la Audiencia Provincial de Madrid de 31 de octubre de 1996; Sentencia de la Audiencia Provincial de Burgos de 20 de diciembre de 2000 (RJ 2000, 10652) y la Sentencia del Tribunal Constitucional de 29 junio 2000 (RTC 2000, 181) que por un lado declara la Constitucionalidad del sistema, y por otro confirma su obligatoriedad (fundamento $4^{\circ}$ ).

52 Como ejemplos de esta tendencia jurisprudencial, pueden ser citadas las siguientes sentencias: Sentencia de la Audiencia Provincial de Madrid de 11 de noviembre de 1996; Sentencia de la Audiencia Provincial de Teruel de 16 de enero de 1997; Sentencia de la Audiencia Provincial de Oviedo de 19 enero 1998 y Sentencia de la Audiencia Provincial de Patencia de 23 de febrero de 1998.

53 Vicente Domingo, Elena, obr. cit. p. 410.

54 Así lo entienden entre otros: Pantaleón Prieto, Fernando, obr. cit. p. 1; Martín Del Peso, Rafael, obr. cit. p. 111. 
de la reparación integral del daño, aunque así parezca desprenderse del criterio 7 del Anexo, puesto que la referencia a la total indemnidad de la víctima no es más que una declaración meramente conceptual que queda vacía de contenido al confrontarse con la mecánica de las tablas de valoración desde las cuales no se puede mantener tal afirmación ${ }^{55}$.

Para finalizar la referencia a las características del sistema español de valoración de los daños derivados de accidentes de circulación, no podemos dejar de subrayar que una de las cuestiones que ha suscitado mayores debates en los Tribunales de Justicia dice relación con la determinación del baremo aplicable. Esta discusión se genera a raíz de que las cuantías indemnizatorias previstas en el anexo se revisan anualmente -conforme al apartado primero punto diez de la ley-, y por tanto, el problema de hacer uso de las distintas revisiones desde que ocurre el accidente hasta que se resuelve en la sentencia definitiva, termina afectando directamente al quantum resultante para evaluar los daños.

Así las cosas, la discrepancia se suscita entre quienes estiman que la cantidad final es la que deriva de la aplicación del anexo vigente al tiempo de dictar sentencia, mientras que, la posición opuesta se manifiesta en un conjunto de sentencias que atienden a la fecha del accidente como determinante del sistema aplicable, fijando las cuantías que en ese momento señalaba el texto legal ${ }^{56}$. Pese a que existen estos dos grandes grupos, se destaca una tesis intermedia que atiende a un momento distinto de los anteriores, como es el de la determinación definitiva de las lesiones y secuelas, concluyendo que el anexo aplicable será por ende, el que se encuentre vigente en tal instante ${ }^{57}$.

\section{La pretendida inconstitucionalidad del sistema de valoración de daños corporales en el Derecho español ${ }^{58}$}

Como punto de partida de esta cuestión, podemos citar la sentencia del Tribunal Supremo español de 26 marzo de $1997^{59}$, la cual declaró que el sistema de baremos introducido por la Ley 30/1995, era de dudosa constitucionalidad, debido a que era

55 En este sentido Vicente Domingo, Elena, obr. cit. p. 410.

56 A favor de esta segunda opinión podemos citar la doctrina contenida en: la Sentencia de la AP de Las Palmas de 21 de junio de 2006, y la Sentencia de la AP de Asturias de 16 de mayo de 2006, entre otras.

57 Martín Del Peso, Rafael, obr. cit. pp. 114 a 125.

58 Una interesante referencia al debate planteado tanto en el Tribunal Supremo como del Tribunal Constitucional Español al sistema de baremos la encontramos en: Barrientos Zamorano, Marcelo, obr. cit. pp. 473 a 483, Díez-Picazo, Luis, Derecho de daños, Civitas, Madrid, 1999, pp. 223 a 234.

59 STS de 26 de marzo de 1997 (RJ 280, 1997) 
contrario a los artículos 14 y 15 de la Constitución. Entendió en su oportunidad el máximo tribunal español que: "los baremos de aplicación voluntaria no vulneran la función de cuantificar los daños a indemnizar propia y soberana de los tribunales jurisdiccionales". Además, de poner en entredicho el carácter vinculante del sistema, cuando lo califica de "pretendidamente obligatorio, no solo en el ámbito del seguro obligatorio, como parece lógico, sino en el del seguro voluntario". Como puede apreciarse, la sentencia citada no hace más que confundir en su actuar a los operadores jurídicos de la época, frente a una materia que desde su instauración venía arrastrando una serie de dificultades e interpretaciones grises.

En efecto, es la citada sentencia del Tribunal Supremo de 26 marzo de 1997, unida a una férrea crítica a la ley por parte de alguna autorizada doctrina ${ }^{60}$, que logran crear un clima de confusión entre las Audiencias Provinciales, que culmina con el planteamiento de una cuestión de inconstitucionalidad, la cual es resuelta, en opinión de algunos de forma incoherente e insuficiente ${ }^{61}$, por la sentencia del pleno del

60 Pantaleón Prieto, Fernando, obr. cit. pp. 1 y ss. y Pantaleón Prieto, Fernando, De nuevo sobre la inconstitucionalidad del sistema para la valoración de daños personales de la ley sobre responsabilidad civil y seguro en la circulación de vehículos de motor /en/ Revista jurídica española de doctrina, jurisprudencia y bibliografía, № 1, 1997, España, pp. 2080 a 2084. Cuyas críticas al sistema pueden resumirse de la siguiente forma: A) el sistema de valoración adolece de numerosas imperfecciones, así, en lugar de una reforma parcial, plantea este autor que sería deseable la elaboración de una ley de indemnizaciones para el caso de lesiones corporales o muerte, de general aplicación a los responsables, particulares o administraciones públicas, englobando tanto a la responsabilidad civil contractual como la extracontractual. Por otro lado la valoración de los daños no patrimoniales derivados de lesiones o muerte, por el contrario deberían quedar sujeta a baremos preestablecidos, conforme a unos criterios determinados, legalmente; B) la ley, en lo tocante a las indemnizaciones, debería establecer, a juicio de este autor, con claridad una serie de extremos que se encontrarían en una situación de grave incertidumbre. En concreto sería conveniente fijar los conceptos y partidas indemnizatorias, además de las personas que tendrían derecho a indemnización, de forma tal que toda persona o toda lesión no incluida en la ley como indemnizable, quedara indudablemente excluida de la posibilidad de ser indemnizada por alguna otra vía. Así los daños de carácter patrimonial derivados de lesiones y muerte deberían ser valorados caso por caso bajo el principio de resarcimiento integral. En cuanto a los daños no patrimoniales, deberían someterse a unas tablas o baremos en los que fueran tenidos en cuenta como factores correctores circunstancias tales como el salario o edad de la víctima, así como las cantidades compensatorias que ésta pudiera percibir por otros conceptos (v. gr. seguridad social), las cuales deberían deducirse de la cantidad asignada en concepto de compensación ; C) el nuevo baremo no solucionará el problema del respeto al principio constitucional de igualdad ante la ley, ya que no existe mayor falta de respeto a dicho principio que tratar igual a casos desiguales, de forma tal que el nuevo sistema basado en el mal entendimiento del principio de igualdad, vulnera frontalmente al aludido precepto constitucional; D) los perjuicios de naturaleza patrimonial derivados de daños a las personas no pueden estar sometidos a baremos indemnizatorios de ningún tipo, fundamentalmente porque la institución de la responsabilidad civil no tiene una función punitiva, ni tampoco la consistente en lograr la redistribución de la renta. En similar sentido se ha pronunciado DíezPicazo, Luis, obr. cit. pp. 233 y 234.

61 De esto da cuenta Vicente Domingo, quien se muestra crítica frente a la solución adoptada por la citada sentencia del Tribunal Constitucional Español. Vicente Domingo, Elena, obr. cit. pp. 414 a 416. 
Tribunal Constitucional de 29 de junio de 200062. Dictamen que por un lado aprecia la conformidad con la Constitución del sistema en su conjunto y en particular de las normas que sostienen las tablas incluidas en el anexo, y por otro, admite la inconstitucionalidad de la tabla $\mathrm{V}$, en el sentido de declarar nulos e inconstitucionales solo el inciso final del apartado c) del criterio segundo y el contenido total del apartado letra B, por ser contrarios con los arts. 9.3 y 24.1 de la Constitución Española.

La mencionada declaración de inconstitucionalidad, sin embargo, no se lleva a cabo de forma absoluta e incondicionada, sino únicamente en cuanto tales indemnizaciones tasadas deban ser aplicadas a aquellos supuestos en que el daño corporal, proviniendo de la incapacidad temporal, tenga su causa exclusiva en una culpa relevante $y$, en su caso, judicialmente declarada, imputable al agente causante del daño ${ }^{63}$.

\section{Hacia la búsqueda de un sistema legal comunitario de valoración de los daños corporales}

Creemos acertada la afirmación que la autora española VICENTE DOMINGO hace a modo de diagnóstico de la realidad imperante en el sistema de valoración de los daños corporales adoptado por España, al afirmar que: "probablemente, ha sido en España en comparación con el resto de los países de nuestro entorno jurídico, en donde se han producido los cambios más drásticos en materia de valoración de los daños corporales. Pues no en vano hemos pasado de tener el sistema de valoración más asistemático de todo nuestro entorno jurídico, sustentado en dos principios básicos (el de la reparación integral del daño y el de la discrecionalidad judicial en la reparación), a tener que asumir una Ley (30/1995, 8 de noviembre de Ordenación y Supervisión de los Seguros Privados), para la que desde el punto de vista jurídico no estábamos ni maduros, ni preparados, por lo que nos ha enfrentado a una solución, que con toda razón se ha calificado como solución, de péndulo muy a la española"64.

Siguiendo este mismo orden de ideas, podemos reflexionar que a casi 16 años desde la aprobación de la Ley 30/1995, las dificultades que ha tenido que enfrentar en el sistema español no han sido menores, como ya tuvimos la oportunidad de apreciar en los enunciados anteriores, el planteamiento de cuestiones de inconstitucionalidad, además de sucesivas críticas por parte de la doctrina y la errática postura adoptada por los tribunales de justicia, no han hecho más que resaltar una serie de

\footnotetext{
62 STC (Pleno) 29 de Junio de 2000 (RC 181, 2000).

63 ROCA i TRIAS, Encarna, obr. cit. pp. 143 y 144.

64 Idem
} 
imperfecciones del sistema de valoración de los daños corporales vigente en este ordenamiento. Por lo tanto, no es difícil darse cuenta que aún quedan muchas interrogantes por resolver y que las numerosas enmiendas del sistema todavía no logran desvanecer.

No obstante lo anterior, surge la esperanza de lograr un sistema legal comunitario de valoración de los daños corporales, el cual, siguiendo la tendencia de la mayoría de los ordenamientos europeos ${ }^{65}$, debiese tener un carácter meramente orientativo y no obligatorio como ocurre con el actual sistema español. Es por ello que miramos con buenos ojos el esfuerzo llevado a cabo por un grupo de juristas y médicos evaluadores que ha tenido la pretensión de marcar la línea de salida hacia la meta de un baremo europeo del daño corporal ${ }^{66}$. A la propuesta anterior, le ha seguido un proyecto de baremo médico aplicable con carácter general a la valoración del daño corporal, cualquiera que sea la fuente generadora de responsabilidad civil.

Como destaca cierta doctrina, desde enero de 2006, rige con carácter oficial en el ámbito de la Unión Europea, un sistema de valoración del daño corporal, de estructura distinta al baremo español de tráfico, el cual es dividido en sistema nervioso, sensorial y estomatológico, donde se incluye el oftalmológico y auditivo, óseo articular, cardiorrespiratorio, vascular, digestivo, urinario, reproductor, glandular-endocrino y cutáneo, que comprende las cicatrices patológicas y quemaduras. Este sistema utiliza para graduar la indemnización criterios porcentuales en forma de porcentajes sobre la plena capacidad, en vez de puntuar las secuelas y tiene carácter orientativo para ser utilizado por los médicos y valoradores del daño corporal que operen en el seno de la Unión. Cabe destacar que dicho sistema, no incluye el lucro cesante, ni la valoración del daño moral derivado del fallecimiento ${ }^{67}$.

Consideramos que los esfuerzos conjuntos de estos grupos de profesionales, son un primer e importante paso para la creación de un sistema legal general que debiera

65 Un estudio reciente al respecto, con abundantes referencias bibliográficas véase en Barrientos Zamorano, Marcelo, obr. cit. pp. 436 a 468.

66 Nos referimos al equipo de profesionales: por un lado juristas, formado por los profesores E. Banakas (Reino Unido), F. D. Busnelli y G. Comandé (Italia), B. Dufwa (Suecia), J. L. Fagnart (Bélgica), H. Groutel (Francia), M. Martín Casals (España), D. Medicus (Alemania), J. F. Sinde Monteiro y M. Manuel Veloso (Portugal) y G. Viney y S. Galand-Carval (Francia). Y por otro médicos evaluadores, formado por los Dres.: P. Lucas (Bélgica), W. Streck (Alemania), C. Borobia (España), H. Hugues-Bejui (Francia), M. Bargagna (Italia) y D. N. Vieira (Portugal), todos bajo la dirección de los profesores Busnelli y Lucas. Más detalles del proyecto de baremación de Busnelli y Lucas, en Martín-Casals, Miquel, ¿Hacia un baremo europeo para la indemnización de los daños corporales?: consideraciones generales sobre el proyecto busnelli-lucas /en/ Revista de derecho patrimonial, № 8, 2002, España, pp. 21 a 34.

67 Martín Del Peso, Rafael, obr. cit. pp. 181 y 182. 
abarcar la indemnización de daños por muerte, el daño físico, psicológico y la incapacidad temporal, pudiendo servir en el futuro de necesaria referencia al sistema español ${ }^{68}$.

\section{Conclusiones}

Entendiendo, por una parte, al régimen de baremos como una de las herramientas que los ordenamientos jurídicos disponen para limitar la excesiva discrecionalidad judicial en la determinación del quantum indemnizatorio de los perjuicios corporales. Y constatando por otra, que los tribunales de justicia chilenos, al pronunciarse sobre casos de daños corporales -gozando por lo demás de una excesiva discrecionalidad al respecto- se han ido alejando del principio de igualdad hasta llegar, en algunos casos, a rayar en la arbitrariedad ${ }^{69}$-fijando cuantías muy diferentes para compensar supuestos similares y cantidades semejantes para compensar supuestos completamente diferentes-. Consideramos de lege ferenda la necesidad de que en el sistema chileno, y en otros similares, se adopten mecanismos tendientes a la racionalización del sistema de valoración de daños corporales, estableciendo así, límites objetivos a la amplia discrecionalidad judicial que imperaría al respecto, que a fin de cuentas produce para el sistema efectos mucho más perniciosos que positivos.

No apoyamos la admisión de un sistema de tasación legal obligatoria de los daños corporales como ocurre en España, particularmente debido a los problemas descritos que se ha suscitado desde su accidentada implementación.

Más bien, somos optimistas respecto de la adopción de un sistema de baremación: no legal; de periodicidad anual; meramente orientativo; de aplicación general a todos los tipos de perjuicios personales; dividido por tipos de lesiones y órganos lesionados; y en el que en su elaboración participen conjuntamente médicos, juristas y jueces. Consideramos además, que su difusión, financiamiento y control debe estar a cargo de entidades públicas y no de empresas aseguradoras, lo cual permitirá independencia, transparencia y aportará la legitimidad de origen necesaria para una utilización adecuada por parte de los órganos judiciales.

68 Martín Del Peso, Rafael, obr. cit. pp. 181 y 182.

69 Así: Corte de Apelaciones de Santiago, 08.09.2003, G) 279, 188 (\$ 15 millones por inmovilidad de por vida de un joven), Corte de Apelaciones de Santiago, 08.04.1999, RDJ, t. XCVI, sec. 5a, 94 (\$ 15 millones por lesiones en el hombro a una mujer que se cayó desde un tablón); Corte de Apelaciones de Concepción, 6.3.2002, confirmada por la Corte Suprema [cas. fondo], 6.3.2002, G) 274, 59 (\$ 65 millones por pérdida de un pezón y necrosis en el tejido de una mama). Una visión crítica con abundantes referencias jurisprudenciales, la encontramos en: Barros Bourie, Enrique, obr. cit. pp. 316 a 318 , notas al pie $n^{\circ} 324$ y 325 . 


\section{Bibliografía}

BACACHE-GIBEILI, Mireille, Les obligations, La Responsabilité civile extracontractuelle / en/ Larroumet, Christian (Dir.), Droit Civil Tomo V. Paris, Economica, 2007.

BARros Bourie, Enrique, Tratado de Responsabilidad Extracontractual, Editorial Jurídica de Chile, Santiago, 2006.

BarRientos Zamorano, Marcelo, El resarcimiento por daño moral en España y Europa, Ratio Legis, Salamanca, 2007.

Carbonnier, Jean, Droit Civil, Les obligations. Tomo IV, Presses Universitaires de France, Paris, $22^{\circ}$ edición, 2000.

Corral Talciani, Hernán, Lecciones de responsabilidad civil extracontractual, Editorial Jurídica de Chile, Santiago, 2003.

De Ángel Yágüez, Ricardo, Algunas previsiones sobre el futuro de la responsabilidad civil (con especial atención a la reparación del daño), Ed. Civitas, Madrid, 1995.

De Ángel YágüEz, Ricardo, Tratado de responsabilidad civil, Ed. Civitas, Madrid, 1993.

De Ángel Yágüez, Ricardo, La reparación de daños personales en el Derecho español, con referencias al Derecho comparado /en/ Revista Española de Seguros $n^{\circ}$ 57, 1989, España.

Díez-Pıcazo, Luis, Derecho de daños, Civitas, Madrid, 1999.

Díez Schwerter, José Luis, El daño extracontractual. Jurisprudencia y doctrina, Editorial Jurídica de Chile, Santiago, 1997.

Domínguez Hidalgo, Carmen, El daño moral, Tomo II, Editorial Jurídica de Chile, Santiago, 2000.

García Serrano, Francisco de Asís, El daño moral extracontractual en la jurisprudencia civil /en/ Anuario de Derecho Civil, T. XXV, 1972, España.

Le Tourneau, Philippe, La responsabilidad civil, Ed. Legis, Bogotá, 2004. (Traducción de Javier Tamayo).

Martín-Casals, Miquel, ¿Hacia un baremo europeo para la indemnización de los daños corporales?: consideraciones generales sobre el proyecto busnelli-lucas /en/ Revista de derecho patrimonial, № 8, 2002, España. 
Martín-Casals, Miquel, Una lectura de la sentencia del tribunal constitucional sobre el baremo /en/ La Ley: Revista jurídica española de doctrina, jurisprudencia y bibliografía, No 6, 2000, España.

Martín Del Peso, Rafael, La indemnización y valoración de daños y perjuicios derivados de la responsabilidad civil /en/ Seijas, José Antonio (coord.), Responsabilidad civil, Aspectos fundamentales, SEPIN: Madrid, 2007.

Medina Alcoz, María, La culpa de la víctima en la producción del daño extracontractual, Ed. Dykinson, Madrid, 2003.

Medina Crespo, Mariano, La valoración civil del daño corporal: Bases para un tratado, Ed. Dykinson, Madrid, 1999.

Medina CRespo, Mariano, La valoración legal del daño corporal: análisis jurídico del sistema incluido en la ley 30/1995, Ed. Dykinson, Madrid, 1997.

Naveira Zarra, Maita, El resarcimiento del daño en la responsabilidad civil extracontractual, Editoriales de Derecho Reunidas, Madrid, 2006.

Pantaleón Prieto, Fernando, De nuevo sobre la inconstitucionalidad del sistema para la valoración de daños personales de la ley sobre responsabilidad civil y seguro en la circulación de vehículos de motor /en/ Revista jurídica española de doctrina, jurisprudencia y bibliografía, No 1, 1997, España.

Pantaleón Prieto, Fernando, Sobre la inconstitucionalidad del sistema para la valoración de daños personales de la Ley sobre Responsabilidad Civil y Seguro en la Circulación de Vehículos a Motor /en/ Revista Actualidad Jurídica Civil Aranzadi, n² 245, 1996, España.

Pradel, Xavier, Le préjudice Dans le droit civil de la responsabilicé, Librairie Genérale de Droit et de Jurisprudente, Paris, 2004.

Reglero Campos, Fernando, Responsabilidad civil y seguro en la circulación de vehículos de motor /en/ Reglero, Fernando (coord.), Tratado de Responsabilidad Civil, Aranzadi, Navarra, 2006.

Roca I TRIAS, Encarna, Derecho de daños: Textos y materiales, $5^{a}$ edición, Tiran lo Blanch, Valencia, 2007.

Rodríguez Grez, Pablo, Responsabilidad extracontractual, Editorial Jurídica de Chile, Santiago, 1999. 
SabAter Bayle, Elsa, El baremo para la valoración de los daños corporales, Aranzadi, Navarra, 1998.

Sainz Moreno, Fernando, Transmisión hereditaria de la indemnización por daños morales (sobre la reforma del parágrafo 847 del Código Civil alemán y la situación en el Derecho español) /en/ Revista de Administración Pública, n. ํ 124, 1991, España.

Vicente Domingo, Elena. El daño /en/ Reglero, Fernando (coord.), Tratado de Responsabilidad Civil, Aranzadi, Navarra, 2008.

Vicente Domingo, Elena, Los daños corporales: tipología y valoración, Bosch, Barcelona, 1994.

Viney, Geneviéve, Jourdain, Patrice, Les conditions de la responsabilicé /en/ Jacques Ghestin (Dir.), Traite de Droit, $3^{\text {a }}$ edición, Librairie Genérale de Droit et de Jurisprudente, Paris, 2006. 